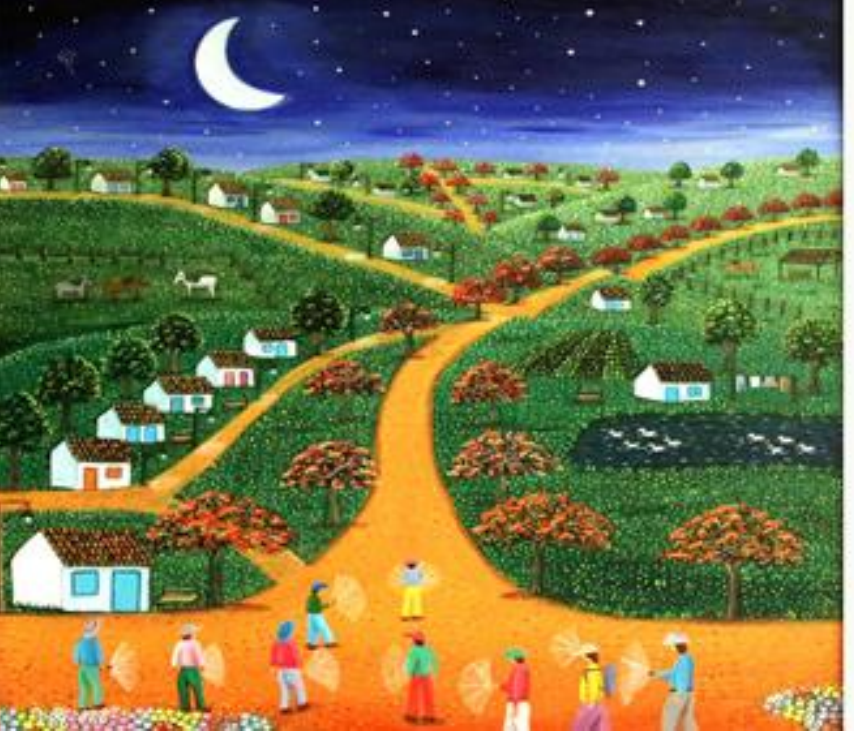

\section{miguilim}

revista eletrônica do netlli

volume 8, número 3, set.-dez. 2019

\title{
“CRIANÇA DE PÉ NO CHÃO AQUI NÃO PODE ESTUDAR": UMA ANÁLISE DISCURSIVA DE CIDADÃO NA CONSTITUIÇÃO DA SOCIEDADE BRASILEIRA
}

\author{
“BAREFOOT CHILD CANNOT STUDY HERE”: A \\ DISCURSIVE ANALYSIS OF CIDADÃO IN THE \\ CONSTITUTION OF THE BRAZILIAN SOCIETY
}

\author{
Carla Cassiano de ALMEIDA \\ Nádia Dolores Fernandes BIAVATI
}

Universidade Federal de São João del-Rei, Brasil

RESUMO | INDEXAÇÃO | TEXTO | REFERÊNCIAS | CITAR ESTE ARTIGO | O AUTOR

RECEBIDO EM 01/07/2019 • APROVADO EM 17/12/2019

\section{Resumo}

Em diálogo direto com as Teorias Críticas da Cultura, o presente trabalho parte de uma perspectiva construtivista de sociedade e de cultura. Propomos questionar, por via da Análise Crítica do Discurso, a letra da canção Cidadão, composta por Lúcio Barbosa e gravada por Zé Geraldo. Compreendemos, a partir da Teoria da Estruturação, de Anthony Giddens (2003), o modo como se constitui a sociedade e como as práticas sociais são ordenadas no tempo e no espaço. Além disso, partimos da noção de cultura que, mesmo em sua complexidade terminológica, pode ser entendida como um modo de significação de um coletivo manifesto 
por suas coesões e incongruências. Tal processo se manifesta no discurso, que compreende, segundo Fairclough (2001), o uso da linguagem como prática social que significa o mundo. Com esses pontos em mente, lançamos mão da proposta de Fairclough (2001) e de alguns conceitos base deste trabalho, como os significados: acional, representacional e identificacional, a intertextualidade e alguns procedimentos para a análise textual, bem como o quadro tridimensional como aporte para a análise discursiva da letra da canção em estudo. Desse modo, conceitos que emergem das práticas sociais a partir de movimentos no corpo da letra da canção possibilitam identificar o agente, que dentro do modelo de estratificação, dialoga com os conceitos de cognoscitividade e consciência discursiva, propostos por Giddens (2003). Assim, além desses conceitos, outros pontos da teoria desse sociólogo refletem e reconstituem os padrões históricos sociais mais amplos de exclusão presentes em Cidadão, considerando o modo como o eu lírico se manifesta, por vezesrevoltado, por vezes resignado à condição de excluído.

\section{Abstract}

In a direct dialogue with the Cultural Studies, the present work departs from a constructivist perspective about society and culture. We propose to analyze, through the Critical Discourse Analysis, the lyrics of the song Cidadão, composed by Lúcio Barbosa and recorded by Zé Geraldo. We understand, based on Anthony Giddens's Theory of Structuring (2003), how society is constituted and how social practices are ordered in time and space. We also start from the notion of culture, which, even in its terminological complexity, can be understood as a mode of signification of a collective manifest due to its cohesions and incongruities. This process is manifested in the discourse, which includes, according to Fairclough (2001), the use of language as a social practice that signifies the world. Bearing this in mind, we make use of Fairclough's (2001) proposal and some basic concepts of his work as the following: ational, representational, identificational, intertextuality and some procedures for textual analysis, as well as the three-dimensional framework as a contribution to the discursive analysis of the song lyrics. Thus, concepts that emerge from social practices represented in movements in the body of the lyrics enables the identification of the agent, who, within the stratification model, dialogues with the concepts of Cognoscitivity and Discursive Consciousness proposed by Giddens (2003). Hence, in addition to these concepts, other aspects of the sociologist's theory reflect and reconstitute the broader social historical patterns of exclusion present in Cidadão.

\section{Entradas para indexação}

PALAVRAS-CHAVE: Constituição da sociedade. Análise Crítica do Discurso. Música. Cidadão. KEYWORDS: Constitution of the Society. Critical Discourse Analysis. Music. Cidadão.

\section{Texto integral}

\section{Introdução}


Partimos dos elementos teóricos propostos pela Análise Crítica do Discurso, mais especificamente o trabalho de Fairclough (2001), para a análise discursiva da letra da canção popular brasileira Cidadão, em um diálogo com os estudos culturais no que se refere à constituição da sociedade. Desse modo, o presente trabalho lança o seguinte questionamento: como se dá a articulação entre o agente (ator social) do discurso, representado pelo "cidadão", e os elementos da Teoria da Estruturação, proposta por Giddens (2003)? Partindo do entendimento de que há uma relação dialética entre o discurso e a estrutura social (FAIRCLOUGH, 2001), o discurso se constitui na/e pela estrutura social, e o agente/ator social reflete historicamente constituído de modos de exclusão social/cultural que se manifestam na letra da canção.

Em sua formulação atual, a música popular brasileira (MPB) tem origem no resultado de manifestações culturais de influência indígena, africana e europeia. Entretanto, o movimento MPB é uma referência à produção musical desenvolvida a partir da década de 1960. Durante esse período, a música foi não apenas um símbolo de resistência mas também um meio de crítica social sobre a sociedade brasileira após o golpe militar de 1964. É nesse contexto que a letra de Cidadão se insere, pois a canção, que foi composta em 1978 pelo poeta baiano Lúcio Barbosa, apresenta vários tipos de restrições que um agente/ator social sofre, em detrimento da constituição social e histórica em que está inserido. Nessas condições, o eu lírico se manifesta por vezes em atitude de queixa, interagindo com um interlocutor, observando que não participa dos bens culturais e dos locais que ajuda a construir, como a escola e o prédio. Desse modo, uma canção se manifesta como uma prática cultural de protesto, condizente com o manifesto contra as opressões sofridas durante a ditadura.

Essa diversidade cultural é normalmente simplificada através da divisão da cultura em apenas dois planos: o da cultura das elites detentoras do poder político-econômico e das diretrizes para os meios de comunicação - que é a cultura do dominador - e a cultura das camadas mais baixas do povo urbano e das áreas rurais, sem poder de decisão política - que é a cultura do dominado. [...]. Em resultado, a cultura das camadas pobres acaba sendo submetida a uma dupla dominação em primeiro lugar, porque se situa em posição de desvantagem em relação à cultura das elites divergentes do país: e, em segundo lugar, porque esta cultura dominante não é sequer nacional, mas importada e, por isso mesmo, dominada (TINHORÃO, 1998, p. 10).

A reflexão contra a dominação e os aspectos coercitivos perpassa os aspectos culturais a serem discutidos a partir da letra da canção em estudo. Considerando esses aspectos culturais indispensáveis para esta discussão, tomamos, segundo Carmo (2014), a cultura como algo indissociável dos modos de vida que caracterizam uma coletividade e que através de uma visão sociossemiótica pode ser entendida como um conjunto de signos e significados elaborados pelos grupos sociais. Essa criação se deve às necessidades 
comunicativas dos sujeitos e é o ponto chave de aproximação com a Linguística Sistêmica Funcional, uma grande influência e base da Análise Crítica do Discurso (CARMO, 2014).

Conforme será exposto ao longo da letra, é possível encontrar relações de dominação, coerção e outros aspectos relativamente marcantes quando da inserção de um homem simples do interior que vai para capital em busca de melhores condições de vida para sua família e só encontra restrições para a vida de um simples 'cidadão'.

Esse conjunto de contingências reflete as condições históricas de desigualdade enquanto as reproduz. E a própria constituição da sociedade implica um conjunto de possibilidades sobre as quais o ator social precisa atuar, a quem é dado o direito de escolher entre alternativas, pode intervir e transformar a possibilidade em acontecimento; assim acontece a dialética social. Contudo, antes de tratarmos de tal tema, é importante delimitar as bases sobre as quais realizamos nossa análise.

\section{0 papel da cultura como ponto de partida para a problematização da constituição da sociedade brasileira}

O entendimento é que o mundo sociocultural é continuamente construído e reconstituído por seus agentes/atores sociais. Dessa forma, direcionamos o nosso olhar para uma breve explanação acerca do conceito de cultura. Em meio à complexidade e à amplitude do termo, optamos por tratá-lo retomando algumas postulações pautadas nos estudos sociais.

Segundo Alves (2010), o termo "cultura" pode ser aplicado de diversas formas, mas em geral, desde o século XVIII, pode ser tudo o que é feito, produzido e reproduzido pelo homem e transmitido por gerações. A fim de afunilar a conceituação de cultura voltada para a constituição científica do termo, Alves (2010) faz uma rápida análise histórica do significado terminológico e apresenta duas grandes dimensões: a subjetiva e a objetiva.

Elas estão presentes desde as origens gregas do conceito de cultura até o advento da sua concepção científica. Na primeira dimensão, cultura diz respeito a uma propriedade ou capacidade do indivíduo de desenvolver suas "faculdades espirituais" através da educação da filosofia, das artes. Portanto, a um crescimento progressivo da pessoa. Paideia, cultura animi, coltura e bildung são variantes terminológicas que indicam a formação intelectual e moral do indivíduo. Na concepção "objetiva", cultura é um produto coletivo, preexistente, exterior, dotado de certa autonomia e constritiva em relação ao sujeito individual. [...] Na sua dimensão "objetiva" tanto no seu aspecto "universalista" (cultura como patrimônio da humanidade) quanto "particularista" (para identificar determinados agrupamentos sociais), como "cultura brasileira", "cultura nordestina", etc., cultura é concebida como 
uma "realidade específica", usualmente concebida como um "sistema", composta por um conjunto de elementos interrelacionados dentro de uma determinada sociedade ou comunidade (ALVES, 2010, p. 44-45).

Nessa perspectiva, percebemos a importância da historicidade que acompanha o conceito, a partir do qual, pelo viés "construtivista", compreende que toda prática cultural está direta ou indiretamente associada à ideia de cultura como "estrutura". Depreendemos, então, a cultura como ação social, ou seja, as novas interações sobre o vínculo social com as questões relacionadas à ação e à historicidade implicam outra escala de análise, mais próxima dos atores sociais.

Ao centralizar a análise em questões de ação social, a perspectiva construtivista, que é ancorada no viés da historicidade, carrega três aspectos importantes: (a) condições herdadas do passado; (b) essas construções são atualizadas nas práticas e nas interações da vida cotidiana dos atores; (c) abertura de possibilidades para o futuro. Assim, o conceito de historicidade apresenta simultaneamente aspectos de "objetivações" e "interiorizações" da realidade social. Dessa forma, a análise construtivista se caracteriza pela concepção de que a cultura não se coloca como uma realidade já dada, mas é constituída na relação com os agentes/atores sociais (ALVES, 2010). Desse modo, os eventos culturais, segundo Tylor (2014), são não meras sucessões, mas conexão entre os eventos registrados estruturalmente. Assim, a prática social é resultante de muitos agentes/atores sociais que estão fora de um determinado campo de observação. Tylor (2014) retoma uma ideia fenomenológica descrita no dito "as árvores o impedem de ver a floresta", ou seja, algumas pessoas se pautam apenas no aspecto individual da vida de outras e não se voltam para a noção de ação em comunidade. Entretanto, alguns estudos sociológicos fazem o caminho inverso, focam apenas na sociedade e se esquecem dos aspectos individuais que a constituem.

$\mathrm{Na}$ tentativa de abordar indivíduo e(m) sociedade, Giddens (2003) apresenta em seu trabalho $A$ constituição da sociedade temas que envolvem elementos da estruturação na teoria social que propõe reflexão acerca do ser e do fazer humano, das reproduções e das transformações sociais. Para ele, as propriedades estruturais dos sistemas sociais só existem na medida em que formas de conduta social são reproduzidas através do tempo e do espaço. Ou seja, as práticas sociais, tomadas em caráter temporal e espacial, estão enraizadas na constituição do sujeito e do objeto social. Segundo Giddens (2003), a Teoria da Estruturação possui três conceitos básicos: "estrutura", "sistema" e "dualidade de estrutura".

A estrutura refere-se, em análise social, às propriedades de estruturação que permitem a "delimitação" de tempo-espaço em sistemas sociais discernivelmente semelhantes por dimensões variáveis de tempo e de espaço, e lhes emprestam uma forma "sistêmica" (GIDDENS, 2003, p. 20). 
Já os conceitos de "sistema" e de "estruturação" retomam e cumprem a função da estrutura e, no que se refere à "dualidade de estrutura", associa-se à proposição de que regras e recursos projetados na produção e na reprodução da ação social são inerentes aos modos de reprodução do sistema. Assim, Giddens (2003) exemplifica o conceito das regras, chamando a atenção para dois aspectos delas: seu papel na constituição do significado e sua estreita conexão com sanções.

Entre os vários pontos da Teoria da Estruturação, retoma-se em Giddens (2003) um conceito chave para o desenvolvimento deste trabalho é o de "coerção".

\begin{abstract}
A coerção refere-se aqui à estruturação de sistemas sociais como formas de poder assimétrico, em conjunto com o qual uma série de sanções normativas podem ser aplicadas contra aqueles cuja conduta é condenada, ou desaprovada, por outros. Como indica o enunciado de Durkheim, as coerções geradas por diferentes tipos de recurso podem variar desde a coerção física nua e crua até os métodos muito mais sutis de coerção se mescle aos outros. Além disso, como sublinhei com firmeza, o poder nunca é meramente uma coerção, mas está na própria origem das capacidades dos agentes de realizar as ações pretendidas (GIDDENS, 2003, p. 205).
\end{abstract}

A partir da teoria da estruturação, Giddens (2003, p. 203) postula que a ação acontece em detrimento das "influências causais do corpo" que perpassam a relação com o mundo material. Nesse sentido, os seres humanos se envolvem em determinadas ações materiais devido a uma seleção da estrutura. Assim, a próxima seção, pretende analisar a letra de Cidadão pelo viés da Análise Crítica do Discurso em um diálogo com a Teoria da Estruturação e os estudos culturais.

\title{
3 A Análise Crítica do Discurso: um caminho para análise da letra da canção
}

A abordagem em Análise Crítica do Discurso (doravante ACD) tem como grande influência para os seus estudos a Linguística Sistêmico-Funcional (HALLIDAY, 1973; 2009; 2014), a qual, como o próprio nome indica, organiza a linguagem em um movimento dialético entre o sistema linguístico e o contexto sociocultural. Essa organização propicia uma reflexão sobre a ação no/do mundo e, por isso, direciona a análise da estrutura para uma análise das práticas sociais.

Nessa perspectiva, as pesquisas em ACD são direcionadas pela linguística e pelo construto social que as perpassa. Fairclough (2001) nos apresenta o discurso, entendido como prática de significação do mundo, através de relações dialéticas entre a linguagem, compreendida como parte irredutível da sociedade. Desse modo, o discurso é visto como prática social, e sua compreensão se dá por meio de representações e identidades que se relacionam com a estrutura da sociedade e as possibilidades de mudança social. 
Sendo assim, o autor apresenta um método de análise multifuncional que considera os textos como representantes das relações sociais que englobam diferentes identidades e perpassam as práticas sociais rumo à transformação social. Embasado nos estudos hallidianos da linguagem, Fairclough (2003) se pauta na ideia multifuncional, ou seja, aquela que considera que os textos se constituem a partir de funções (ou metafunções) simultâneas em sua constituição, que são ideacionais, interpessoais e textuais. Essa ideia é muito importante, pois parte do pressuposto de que os textos partem de escolhas e da construção de sentidos, que não se dão ao acaso, mas acontecem a partir da perspectiva de interlocução gerada e carregam, por meio dessas escolhas de dizeres, um modo de ser e de agir no mundo. Assim, os textos representam simultaneamente aspectos das relações sociais e das práticas sociais que constituem o mundo social.

\begin{abstract}
Com base na LSF de Halliday, especificamente relendo suas metafunções, Fairclough (2001) propõe uma divisão da metafunção interpessoal em identitária e relacional, a primeira para análise das formas de estabelecimento das identidades sociais dentro do discurso e a segunda para análise de como as relações sociais entre os participantes do discurso são engendradas em termos de representação e negociação, o que parece ter apoio em pensamentos a partir dos quais "tanto os indivíduos quanto os grupos constroem, negociam e defend[e]m sua identidade ou auto compreensão" (EDGAR; SEDGWICK, 2003, p. 169 apud CARMO, 2014, p. 71).
\end{abstract}

Fairclough (2003) retoma a noção de metafunção(ões), e a recontextualiza por intermédio da operacionalização de três significados: acional, representacional e identificacional. Desse modo, sua proposta articula a relação do texto com o evento à medida que ele acontece como ação social representando em um estilo o modo de ser e de reconstituir a realidade com o mundo físico e social mais amplo e com as pessoas envolvidas no evento a partir dos significados. Considerando esses aspectos da teoria bem como a concepção tridimensional do discurso, a intertextualidade e alguns elementos da análise textual, a análise será desenvolvida a seguir.

A canção Cidadão composta por Lúcio Barbosa ganhou notoriedade na voz de Zé Geraldo e posteriormente foi regravada por outros artistas, como Zé Ramalho, Luiz Gonzaga e Renato Teixeira. Hoje, após quarenta anos de seu lançamento, ainda reflete a realidade social de muitos brasileiros.

Inicialmente nos voltamos para título Cidadão, que, segundo o dicionário online da língua portuguesa (2018) é um substantivo masculino que nomeia "um indivíduo que, por ser membro de um Estado, tem seus direitos civis e políticos garantidos, tendo que respeitar os deveres que lhe são conferidos/pessoa que habita uma cidade". A palavra "cidadão" é utilizada na canção através da função metalinguística da linguagem. 0 eu lírico faz referência à presença de um "cidadão proibido de entrar nos lugares que ajudou a construir, por outro lado, ele não é capaz de se colocar como um "cidadão", pois pelas ações sociais descritas nos 
versos, os direitos não lhe são garantidos quando ele é impedido, de alguma maneira, de frequentar esses locais.

Diante disso, buscamos em Fairclough (2003) o significado identificacional. Para o autor, em meio à complexidade da identidade, há uma relação dialética entre estrutura social e ação individual. Além disso, a identificação acontece por meio da junção de aspectos discursivos e os aspectos inerentes à sua exterioridade, e só assim as identificações ou autoidentificações podem ser reproduzidas ou transformadas. Na nomeação de "cidadão", o eu lírico se posiciona em oposição ao "cidadão" que o impede de entrar em determinados locais, o que se deve à classificação social em que o "cidadão pobre" se identifica. Resende e Ramalho (2006, p. 77) postulam que

[...] a identidade e a diferença relacionam-se, pois, às maneiras como a sociedade produz e utiliza classificações, por isso são conceitos importantes em teorias críticas, interessadas na investigação de relações de dominação - o privilégio de classificar implica o privilégio de atribuir valores aos grupos classificados.

Assim, ao se referir a tais classificações socialmente impostas, o eu lírico afirma (ou nega) sua identidade no/pelo discurso, retomando Fairclough (2001, p. 122), que trata hegemonia como lutas entre grupos sociais assimetricamente situados que "[...] para construir, manter ou romper alianças e relações de dominação /subordinação, assumem formas econômicas, políticas e ideológicas".

A letra da canção apresenta uma narrativa da saga de um eu lírico que trabalha como pedreiro, constrói edifício, colégio, igreja, mas, devido à sua condição social, recebe restrições de frequentar aqueles locais e é impedido até de admirar o prédio que construiu. Desse modo, a percepção de aspectos presentes na Teoria da Estrutura (GIDDENS, 2003) pode ser observada no excerto a seguir:

Tá vendo aquele edifício moço?

Ajudei a levantar

Foi um tempo de aflição

Eram quatro condução

Duas pra ir, duas para voltar

Hoje depois dele pronto

olho pra cima e fico tonto

Mas me chega um cidadão

e me diz desconfiado, tu tá aí admirado

ou tá querendo roubar?

Meu domingo tá perdido

Vou pra casa entristecido 
Dá vontade de beber

E pra aumentar meu tédio

Eu nem posso olhar pro prédio que eu ajudei a fazer.

(BARBOSA, 1978)

A admiração e o orgulho pelo trabalho desenvolvido logo são desestimulados pelo questionamento do "cidadão": “Tu tá aí admirado ou tá querendo roubar?". Dessa maneira, o trecho da letra remete ao que é chamado por Giddens (2003) de "monitoração reflexiva da ação", em que os agentes controlam, regulam e monitoram o fluxo de atividades, tanto as suas quanto as de outros. A inibição e o desconforto são provados no "cidadão" da classe operária e atuam como controle de ser e estar em algum lugar; por outro lado, uma classe dominante, representada por um "cidadão" de classe burguesa, regula e restringe o que é posto hegemonicamente.

Para Giddens (2003), o sistema social reflete como nas/e pelas atividades os agentes reproduzem as condições que possibilitam as práticas e as ações sociais. Nessa perspectiva, o autor apresenta o conceito de "cognoscitividade", que em linhas gerais, é tudo que se dispõe através do conhecimento tácito, ou discursivo e que atua como modos de produção e reprodução das ações dos próprios atores ou de outros que estão envolvidos na esfera social.

Nesse viés, podemos retomar outro conceito de Giddens (2003) nomeado por ele de "consciência discursiva" e baseado na ideia de que os atores expressam verbalmente ditos acerca de suas condições sociais, o que pode ser percebido durante a letra da canção. 0 trecho a seguir, além de retomar os dois últimos conceitos, apresenta a "coerção", que segundo Giddens (2003), está associada às sanções e ao modelo estrutural da sociedade.

Tá vendo aquele colégio moço?

Eu também trabalhei lá

Lá eu quase me arrebento

Pus a massa fiz cimento

Ajudei a rebocar

Minha filha inocente

vem pra mim toda contente

Pai vou me matricular

Mas me diz um cidadão

Criança de pé no chão

aqui não pode estudar

Esta dor doeu mais forte

por que que eu deixei o norte 
eu me pus a me dizer

Lá a seca castigava mas o pouco que eu plantava

Tinha direito a colher

(BARBOSA, 1978)

O trecho começa novamente com a narrativa do "cidadão", que trabalha como pedreiro e se orgulha de construir lindos imóveis. Desta vez, a construção é um colégio em que a filha almeja estudar. No entanto, mais uma vez, "o cidadão" eu lírico descreve a situação de coerção quando apresenta os dizeres prováveis à condição da filha, incapaz de frequentar o colégio construído pelo pedreiro: o trecho "Criança de pé no chão aqui não pode estudar" refere-se à filha do pedreiro que ali pretende se matricular, mas é impedida por sua condição social. No que diz respeito aos aspectos coercivos como o presente na letra da música, Giddens (2003, p. 206) postula:

Voltando ao poder enquanto forma de coerção, cumpre sublinhar que ele é o meio de conseguir que as coisas sejam feitas; em definitivo, é tanto facilitador quanto coercivo. Os aspectos coercivos do poder são experimentados como sanções de vários tipos, indo desde a aplicação direta da força ou da violência, ou a ameaça disso, até a expressão moderada de desaprovação.

Nessa perspectiva, a coerção acontece não apenas com o pedreiro - um "cidadão" pobre, com poucas condições e, como a maioria das pessoas de classe baixa, tem apenas nos estudos um modo de ascensão social - mas também com sua filha. Desse modo, a menina pobre que sonha estudar é coercivamente reprimida ao ouvir: "criança de pé no chão aqui não pode estudar". Os aspectos da constituição estrutural da sociedade são exemplificados por esse dito, uma vez que a canção descreve as diferentes gerações perpassadas pela marca da exclusão, de lugares demarcados para determinadas classes. Assim, logo que alguém sonha adentrar o lugar que historicamente não lhe pertence, é inibido por um "cidadão" que detém determinado poder, seja político, seja econômico-social, seja discursivo.

Outro aspecto perceptível no trecho transcrito acima é a "modalização", a qual, segundo Fairclough (2003) assume uma categoria ampla que inclui os polos, nesse caso, exemplificada pelo modalizador discursivo "quase" em "Lá eu quase me arrebento". Além disso, o autor desenvolve outra reflexão acerca das distinções temporais, o que se pode ou poderia, o que deve ou deveria, ou seja, traços que coincidem a distinção entre o hipotético e o não hipotético. Nesse viés, essa distinção pode ser percebida neste trecho:

Esta dor doeu mais forte

por que que eu deixei o norte 
eu me pus a me dizer

Lá a seca castigava mas o pouco que eu plantava

Tinha direito a colher

(BARBOSA, 1978)

Assim, a situação hipotética de permanecer na Região Norte se contrapõe ao momento que o "cidadão" está passando na Região Sudeste, considerando a condição de ser do Norte brasileiro e de estar no Sudeste, sujeito às condições de vida de exclusão dos bens de consumo e de acesso aos lugares.

0 trecho a seguir, que finaliza a canção, faz referência a um imóvel, que abriga espacialmente uma das instituições mais antigas do mundo: a Igreja.

Tá vendo aquela igreja moço?

Onde o padre diz amém

Pus o sino e o badalo

Enchi minha mão de calo

Lá eu trabalhei também

Lá sim valeu a pena

Tem quermesse, tem novena

e o padre me deixa entrar

Foi lá que Cristo me disse

Rapaz deixe de tolice

Não se deixe amedrontar

Fui eu quem criou a terra

Enchi o rio fiz a serra

Não deixei nada faltar

Hoje o homem criou asas e na maioria das casas

Eu também não posso entrar

(BARBOSA, 1978)

Desse modo, o "cidadão", como um sujeito do Norte, representa a condição de único local em que pode participar. A canção faz remissão à participação na quermesse e na novena, dois eventos da Igreja em que o nortista manifesta pertencimento e permissão para manifestar sua religiosidade e devoção, quando o eu lírico demonstra a fé que deposita na figura cristã, em que Cristo se relaciona também à condição de excluído, assim como o eu lírico, quando ambos são postos pela sociedade e pelos outros "cidadãos" sujeitos à exclusão. 


\section{Considerações finais}

Considerando a análise, podemos salientar que ficam relativamente claros os modos pelo quais um contexto cultural exclui e marginaliza o cidadão, aspectos representados na letra em questão. Esse apontamento se expressa através da constituição da sociedade, no modelo da estruturação, nas sanções e nas coerções, rememorados de modo significativo na canção Cidadão.

Ao tomarmos como base as referências socioculturais refletidas na letra da canção, foi possível detectar as diferenças relativamente marcantes que são meios de exclusão do cidadão. Isso nos leva a compreender que, quando um "cidadão tenta adentrar" locais socialmente destinados a outra classe social, logo ele é coercitivamente reprimido.

Além disso, foi possível apontar na letra da canção a presença de uma identidade cidadã que não se coloca enquanto "cidadão", por não possuir bem materiais e por não se inserir em uma classe social privilegiada. 0 processo de constituição, que gera uma estruturação social excludente, atua diretamente na identidade dos atores sociais. Assim, conforme articulado por Alves (2010), esses processos reconstituem a realidade cultural de seus agentes, contribuindo, assim, para a manutenção de arranjos históricos de desigualdade.

Finalmente gostaríamos de chamar atenção para alguns pontos relativos às nossas conclusões. Nosso material de análise, uma canção dos anos 1970, ainda reflete as condições de exclusão e de desigualdade da sociedade brasileira atual. Os aspectos inicialmente pontuados para a análise foram observados na letra e reafirmaram o modelo excludente de sociedade em que vivemos e que perpassa os atores de modo coercitivo.

\section{Referências}

ALVES, P. C. Origens e constituição científica da cultura. In: leituras. Bauru, SP: EDUSC; Salvador: EDUFBA, 2010. p. 21-48. (Org.). Cultura: múltiplas

FAIRCLOUGH, N. Analysing discourse: textual analysis for social research. London: Routledge, 2003.

FAIRCLOUGH, N. Discurso e mudança social. Tradução de Izabel Magalhães. Brasília: Editora Universidade de Brasília, 2001.

GIDDENS, A. A constituição da sociedade. São Paulo: Martins Fontes, 2003.

TINHORÃO, J. R. História social da música popular brasileira. São Paulo: Editora 34, 1998.

TYLOR, E. B. A ciência da cultura. Rio de Janeiro: Expresso Zahar, 2014. 
ZÉ GERALDO. Cidadão. 1979. Disponível em: <https://www.letras.mus.br/ze-geraldo/68686>. Acesso em: 28 jun. 2019.

\section{Para citar este artigo}

ALMEIDA, Carla Cassiano; BIAVATI, Nádia Dolores Fernandes. "Criança de pé no chão aqui não pode estudar": uma análise discursiva de Cidadão na constituição da sociedade brasileira. Miguilim - Revista Eletrônica do Netlli, Crato, v. 8, n. 3, p. 410-422, set.-dez. 2019.

\section{As autoras}

Carla Cassiano de Almeida é professora Substituta do IFMG - Campus Bambuí, aluna do Programa de Mestrado em Letras: Teoria Literária e Crítica da Cultura Linha de Pesquisa Discurso e Representação Social da Universidade Federal de São João del-Rei.

Nádia Dolores Fernandes Biavati é professora adjunta da Universidade Federal de São João del-Rei, professora integrante do Programa de Mestrado em Letras: Teoria Literária e Crítica da Cultura - Linha de Pesquisa Discurso e Representação Social. 